Article

\title{
Winter Pruning: Effect on Root Density, Root Distribution and Root/Canopy Ratio in Vitis vinifera cv. Pinot Gris
}

\author{
Diego Tomasi ${ }^{1}$, Federica Gaiotti ${ }^{1}$, Despoina Petoumenou ${ }^{2}$, Lorenzo Lovat ${ }^{1}$, Nicola Belfiore ${ }^{1}$, \\ Davide Boscaro ${ }^{1}$ and Giovanni Mian ${ }^{3, *}$ (i) \\ 1 Council for Agricultural Research and Economics-Research Centre for Viticulture and Enology, Viale 26 \\ Aprile, 31015 Conegliano, Italy; diego.tomasi@crea.gov.it (D.T.); federica.gaiotti@crea.gov.it (F.G.); \\ lorenzo.lovat@crea.gov.it (L.L.); nicola.belfiore@crea.gov.it (N.B.); davide.boscaro@crea.gov.it (D.B.) \\ 2 Laboratory of Viticulture, Department of Agriculture Crop Production and Rural Environment, University of \\ Thessaly, 38446 Volos, Greece; petoumenou@agr.uth.gr \\ 3 Department of Agricultural, Food, Environmental and Animal Sciences, University of Udine, Via delle \\ Scienze 206, 33100 Udine, Italy \\ * Correspondence: giovanni.mian@outlook.it; Tel.: +39-3478890182
}

Received: 11 August 2020; Accepted: 29 September 2020; Published: 4 October 2020

\begin{abstract}
As in any other plant, the grapevine roots play a vital role in terms of anchorage, uptake of water and nutrients, as well as storage and production of chemicals. Their behaviour and development depend on various factors, namely rootstock genetics, soil physical and chemical features, and field agronomic practices. Canopy management, involving techniques such as defoliation and pruning, could greatly influence root growth. To date, most of the studies on grapevine winter pruning have focused on the effects on yield and quality of the grapes achievable through different pruning systems and techniques, while knowledge regarding root distribution, development, and growth in relation to winter pruning is still not completely understood. In this context, the purpose of our study was to investigate the effect of winter pruning on the root system of field-grown Vitis vinifera cv. Pinot Gris grafted onto rootstock $\mathrm{SO} 4$. We compared two pruning treatments (pruned-P and no pruned-NP) and analysed the effect on root distribution and density, the root index, and the root sugar reserve. Root data were analysed in relation to canopy growth and yield, to elucidate the effect of winter pruning on the root/yield ratio. Our data indicated that: (1) winter pruning stimulated the root growth and distribution; (2) canopy development was not negatively affected by this technique; (3) no pruned treatment produced less growth of the roots but a larger canopy. Information regarding both root growth and root canopy ratio is important as it gives us an understanding of the relationship between the aerial and subterranean parts of the plant, how they compete, and finally, offers us the possibility to ponder on the cultural practices.
\end{abstract}

Keywords: grapevine; winter pruning; root distribution; root density; root growth; root/canopy ratio; root/yield ratio

\section{Introduction}

Understanding the relationship between the above-ground vine growth and the root system dynamics, their competition, and in general, recognizing the grapevine response to agronomic practices that affect the above or below-ground structures, is very important to achieve root/canopy balance and to optimise vineyard management. 
The root system plays some vital roles in the overall plant development, determining the anchorage, the exploration of the soil in search of nutrients and water, the production of regulatory hormones, and as a source of reserve substances and carbohydrates [1,2].

Aerial and subterranean environmental conditions, along with cultural practices, influence root growth and, therefore, the root/canopy ratio [3,4].

Root development can be affected by several factors, including genetics: the rootstock can influence root growth and distribution. In fact, previous studies on rootstocks AXR1, 110R, and St. George revealed different behaviours in terms of root anchorage, uptake of nutrients from the soil, root density and growth, as well as canopy development and fruit production [5]. Hence, due to their specific genetic origin, the various rootstock genotypes have different root-system sizes, in terms of their horizontal and vertical distribution, and their ability to adapt to soil conditions [6]. Among the environmental factors, the soil physical characteristics play a crucial role on root development. Soil depth is directly related to the volume of soil explorable by the root system $[7,8]$ and, generally, deeper soils encourage more roots than superficial soils [9]. Soil layering and texture also affect root distribution: in soils with high clay content the roots are concentrated in the upper soil layer, whereas in soils with low clay content vine roots are more evenly distributed all along the soil profile $[3,5,10,11]$. The physical properties of the soil also influence soil water availability and, consequently, vine root density and distribution, due to the stimulus that water exerts on the root growth. It has been demonstrated that drip irrigation can stimulate root density immediately under the dripper outlet [12]. In this wet area, the production of new roots and the expansion of the root diameter and length is greater than in other areas [13]. Organic matter and availability of nutrients in the soil can affect root growth as well [14-16]. Compost amendment showed a noticeable effect on root density and distribution; for example, the application under vine row of compost derived from vine wood pruning showed a great stimulating effect on root growth, leading to improved horizontal and vertical root development [17].

Also, the presence of cover crops affects vine root distribution: under cover grass, the number of vine roots was found to be larger close to the vines (under row) where there were no cover crops [18,19], and also, in general, in the upper soil layers [20]. This confirms the plasticity of grapevine root systems and their high sensitivity to the soil conditions.

Additionally, canopy management could affect root development. Partial canopy defoliation showed a positive effect on root density at all soil layers, as well as root development in fine to medium diameter classes, which suggested a more efficient nutrient absorption capacity and exploration of soil of these vines [21]. It has been reported that the root systems respond to larger and better developed canopies by increasing activity via changing balances between fine and thicker roots [4]. Root systems can also be affected by winter pruning. Comas et al. (2005) [22] in a long-term study, found that under minimal canopy pruning, the root production was generally greater even though pruning influence could vary from year to year depending on the annual weather conditions [23]. They found that pruning improved the ability of the vine to respond to the variable environmental factors in different years by guaranteeing better root function in terms of water and nutrient supply compared to no pruned vines. Hence, canopy management is crucial to balance vines in terms of root to canopy development, contributing to a greater vine plasticity to variable weather conditions that might occur in different growing seasons.

We can therefore state that above-ground management (canopy and soil management, capable of varying the source-sink relationship of the plant) could be crucial for the root system size, structure, distribution, and density. [16,21,24].

Along with vineyard management, cultural techniques could affect root distribution. High planting densities can reduce the root system size because of plant competition: specifically, with higher vine density per unit area, roots tend to explore soil more in depth than in the case of lower vine density [25,26]. Grapevine roots were also reported to be affected directly by both root pruning and soil tillage: because of these practices, changes in terms of vegetative growth, crop yield, and grape composition were found [27]. 
The existing balance between subterranean and aerial growth of grapevines is very important to better understand how canopy management practices can influence the root system [12,22,24,28,29]. Up to date, most of the research on pruning methods and/or minimal pruning of grapevines has focused on the effects on canopy growth, yield, grape and wine composition [30-33], while still limited information has been gathered regarding the effects of the pruning techniques on the root system and development.

Canopy and roots are related: roots can be fully considered an interface between plant and soil and their number and biochemical functions are determined by the behaviour of the canopy [34].

To increase knowledge on the relationship between canopy management techniques and root system development, in this study, we compared the effect of winter pruning and no pruning applied on Pinot Gris vines, and analysed the vine responses in terms of canopy and root development and root/canopy ratio. Pinot Gris was selected for this study, as it currently ranks fourth among Vitis vinifera cultivars grown in Italy, with 15,907 ha in the Veneto region (north-east of Italy) with a production of 1,225,000 q, used for the production of "DOC delle Venezie wines" (Avepa, 2020 http://dati.istat.it).

\section{Materials and Methods}

\subsection{Plant Material and Experimental Setup}

The trial was conducted in the period 2011-2012 in Ponte di Piave (Treviso, Italy) (45 $42^{\prime} 26.45^{\prime \prime}$ N, $12^{\circ} 27^{\prime} 49.31^{\prime \prime}$ E), in a vineyard of Vitis vinifera cv. Pinot Gris (clone R6) grafted onto SO4 rootstock. The vines were established in 2000 and trained to a free-cordon trellis set $1.50 \mathrm{~m}$ above ground with one support wire. Vine spacing was $0.90 \mathrm{~m} \times 2.50 \mathrm{~m}$ (intra and inter row) for a density of 4,400 vines/ha. The vine rows were approximately $150 \mathrm{~m}$ long and east-west oriented.

From the third year of planting, once the vines were completely trained to a free cordon system, six adjacent rows were selected for this study and two treatments- $\mathrm{P}$ and NP-were applied (three adjacent rows for $\mathrm{P}$ and three for NP) and performed in the same way every year. The $\mathrm{P}$ was carried out on 26th February 2012 and 3rd March 2013 using a tractor-mounted cutter bar unit with a cut profile applied at about $20 \mathrm{~cm}$ from the cordon; hand clean-up was performed by two field workers with pneumatic shears, leaving approximately 50 buds per vine. In the NP vines no winter pruning was performed. NP canopy management in late spring and early summer was limited to a light mechanical trimming of the vegetation at $\sim 40 / 50 \mathrm{~cm}$ above vineyard floor to both optimise the operating conditions for the machines and prevent disease and pests that could attack the grapevines.

In the P treatment, the canopy was trimmed two or three times during the vegetative period, as is common practice for free cordon training systems, in order to promote an upward oriented growth and stimulate lateral growth.

Local standard practices were followed for pest management and fertilisation for both treatments. Fertilisation was carried out in early spring and autumn, applying the same amount ( $300 \mathrm{~kg} / \mathrm{Ha})$ of a balanced fertiliser $(15 \mathrm{~N}, 10 \mathrm{P}, 20 \mathrm{~K}+\mathrm{Mg}+\mathrm{S})$ in both study-years. Plant-defence agrochemicals against pest and fungal disease were applied during the season, adopting commercial products to have an initial defence with copper and sulphur, then systemic products in the middle of the season, and finally, copper and sulphur applied until the end of the treatment period (end of July). Plant agrochemicals were used in the same quantity for both $\mathrm{P}$ and NP vines, with the same number of treatments per year of study. The vines were irrigated by a drip subsoil irrigation system according to the weather conditions. Vine measurements were taken in three random blocks (each block consisting of 15 contiguous vines); each block was located in one of the three internal rows of each treatment (P, NP), except for the defoliated vine selected randomly along the internal row.

\subsection{Pedological and Climatic Characterisation of the Study Site}

The soil of the experimental vineyard was characterised at the beginning of the experiment: nine samples of about $1 \mathrm{~kg}$ of intact soil ( 3 samples taken at $0-0.30 \mathrm{~m}, 3$ samples taken at $0.30-0.60 \mathrm{~m}$ and 3 
at $0.60-0.90 \mathrm{~m}$ ) were randomly collected along the six experimental rows. The samples were analysed by an external laboratory which applied standard methods, as indicated by Italian Law Decree $\mathrm{n}$. 79/1992 [35] and Law Decree n. 185/1999 [36], adopted by Gaiotti et al., 2017 [17]. Analysis of the samples confirmed the homogeneity of the soil within the plot selected for this experiment. Climatic data (temperature and rainfall) were collected hourly by the ARPAV meteorological station of Ponte di Piave (Treviso, Italy). The following parameters were calculated: Growing degree days; GDD, base $10{ }^{\circ} \mathrm{C}$, rainfall $(\mathrm{mm})$, total rainfall, mean temperature of the two years of study; mean temperature and rainfall from 1st April to 30th September and per month in the vegetative period.

\subsection{Grapevine Root Studies}

The profile wall method suggested by Böhm 1979 [37] was used to determine root distribution (vertical and horizontal) and density in P and NP vines. In January 2013, during the dormant period, four vines per treatment with similar scion circumferences were selected within the measuring blocks, first at a distance of $1.00 \mathrm{~m}$ and then at $0.40 \mathrm{~m}$ from the vine trunk. At each distance, roots were counted by using a $1.00 \mathrm{~m}$ high and $1.00 \mathrm{~m}$ wide grid system positioned against the profile wall keeping the grapevine trunk central. The grid was divided in $0.20 \mathrm{~m} \times 0.20 \mathrm{~m}$ inner frame enabling us to plot the position of the roots. The roots were plotted at five different depths $(0-20 \mathrm{~cm}, 20-40 \mathrm{~cm}, 40-60 \mathrm{~cm}$, $60-80 \mathrm{~cm}, 80-100 \mathrm{~cm}$ ) and were classified into three thickness categories according to diameter: $\varnothing$ $<2.0 \mathrm{~mm}=$ fine roots; $2.0<\varnothing<5.0 \mathrm{~mm}=$ medium roots and $\varnothing>5.0 \mathrm{~mm}=$ permanent roots. Root attribution to size classes was performed by visual inspection when size differences were clear, and by measuring root diameter with a portable calibre when there were uncertainties between two adjacent root categories. The processed data are expressed as root number $/ \mathrm{m}^{2}$.

\subsection{Leaf Area Development and Canopy Characteristics}

In 2011 and 2012, at maximum canopy development (typically mid-July, which means around veraison), six vines per treatment, selected randomly within the internal rows, were completely defoliated. For each vine, the number of shoots was counted, and all the leaves collected were positioned on a $1.00 \mathrm{~m} \times 1.00 \mathrm{~m}$ panel and photographed using a digital camera. The photos were processed with the Image program (Version: ImageJ 1.x, National Institutes of Health, 9000 Rockville Pike, Bethesda, MD, USA), and the following parameters were recorded: number of leaves, leaf size, and total leaf area per vine.

At the same time of the vine defoliation, in order to assess the canopy structure and density, Point Quadrat Analysis was performed as described by Smart \& Robinson 1991 [38] on six vines selected within the three measuring blocks of each treatment. A square grid $(0.10 \mathrm{~m} \times 0.10 \mathrm{~m}$ size $)$ of $1.00 \mathrm{~m}$ size, was positioned vertical to the fruit zone and moved to cover most of the canopy. A thin 1.0 $\mathrm{m}$-long metal rod was horizontally inserted into the fruiting zone of the vines, counting contacts made with leaves, clusters or gaps. In this way, each canopy was assessed, at least 800 to 1,000 times to obtain reliable and representative data. Percent gaps, leaf layer number (LLN), percent interior leaves, and percent interior clusters were recorded as follows: $\%$ gaps $=$ total gap to total insertions ratio $\times 100$, LLN $=$ total leaf contacts to total insertions ratio, $\%$ interior leaves $=$ interior leaves to total recorded leaf ratio $\times 100, \%$ interior clusters $=$ interior clusters to total recorded cluster ratio $\times 100$.

\subsection{Yield, Yield Components, and Berry Chemical Composition}

Both treatments were harvested at the same technological maturity, defined as total soluble solids (TSS) $>18^{\circ}$ Brix and titratable acidity (TA) $<9 \mathrm{~g} / \mathrm{L}$ (i.e., tartaric acid). Harvest was carried out on different dates and about one week apart for the NP vines compared to P vines (21 and 15 August in 2011, 26 and 18 August in 2012, for NP and P respectively). All the 15 vines from each block (total 45 vines per treatment) were individually hand-picked; yield, and total number of clusters per vine were recorded and average cluster weight was calculated. The fruit composition at harvest was measured on a sample of $1.0 \mathrm{~kg}$ of grapes collected randomly from all vines of each block. Soluble 
solids were measured by refractometer (Atago PR32) at $20^{\circ} \mathrm{C}, \mathrm{pH}$ and titratable acidity (expressed as $\mathrm{g} / \mathrm{L}$ of tartaric acid) were measured using an automatic titrator (Crison Micro TT 2022, Riera Principal, 34-36 08328, Alella (Barcelona), Spain) by titration with $0.1 \mathrm{~N} \mathrm{NaOH}$. Winter pruning wood from the 15 vines of each block (total 45 vines) was weighed electronically by means of a hanging scale ( $\mathrm{CH}$, Kern, Germany) on 26th February 2012 and 3rd March 2013, as an indicator of vine canopy growth.

\subsection{Root to Canopy Ratios}

To evaluate the relationship between the above-ground and subterranean growth, two ratios were calculated: one was the root to canopy ratio, obtained by dividing root number which resulted in each treatment in 2013 by the respective leaf area of both precedent years $(2011,2012)$; the other was the root to yield ratio, obtained similarly, by dividing root number (2013) of each treatment by the respective vine yield in 2011 and 2012.

\subsection{Carbohydrates Storage in Cane Wood and Roots}

In January 2013, at the same time of root counting, samples of thick roots and canes (between node 4 and 5) were collected and the carbohydrate concentration was determined on three replicates per organ and per treatment, according to a colorimetric method [39] using anthrone reagent (Merck, Darmstadt, Germany). Absorbance readings at $620 \mathrm{~nm}$ were performed using a Shimadzu UV Mini-1240 spectrophotometer (Kyoto, Japan).

\subsection{Statistical Analysis}

One-way analysis of variance was performed using STATISTICA version 8 (StatSoft, Inc., 2300 East 14th Street, Tulsa, OK, USA). Statistical analysis for the determination of significant differences between treatment means was carried out applying the Student-Newman-Keuls test $(p \leq 0.05)$.

\section{Results}

\subsection{Characterisation of the Study Site}

The average value of the physical and chemical characteristics of the soil are reported in Table 1. Soil texture is classified as silt loam (USDA, 2005) in every layer. Along the profile, soil was calcareous while the amount of organic matter was in a range between 0.65 and $1.50 \mathrm{~g} / \mathrm{kg}$, with the maximum levels found in the first layer and the minor percentage in the lower one. $\mathrm{pH}$ resulted alkaline, but in an optimum range for nutrient uptake [40].

The study area enjoys a typical Mediterranean climate, with warm summers and cool winters. Annual rainfall was approximately $800 \mathrm{~mm}$, concentrated mainly in spring and autumn. In the two study years the mean temperatures were quite similar, while rainfall in the vegetative period (April-September) was more abundant in 2012 compared to 2011 (Table 2). 
Table 1. Physical and chemical soil characteristics at three soil depths (0-0.3 m, 0.3-0.6 m, 0.6-0.9 m) of the experimental site.

\begin{tabular}{cccc}
\hline \multicolumn{3}{c}{ Experimental Site } \\
& \multicolumn{3}{c}{ Depth } \\
\cline { 2 - 4 } Parameter & $\mathbf{0 - 0 . 3 ~ \mathbf { ~ }}$ & $\mathbf{0 . 3 - 0 . 6 ~ \mathbf { ~ }}$ & $\mathbf{0 . 6 - 0 . 9} \mathbf{~ m}$ \\
\cline { 2 - 4 } & & & \\
\hline Sand $(\%)$ & 37.5 & 38 & 22.5 \\
Silt $(\%)$ & 44.5 & 48 & 67.5 \\
Clay $(\%)$ & 18 & 14 & 10 \\
Organic matter $(\mathrm{g} / \mathrm{kg})$ & 1.5 & 0.95 & 0.65 \\
Total nitrogen $(\mathrm{N} \%)$ & 0.6 & 0.7 & 0.7 \\
pH (soil/water ratio $=1: 2.5)$ & 8.2 & 8.15 & 8.25 \\
Total carbonates $(\mathrm{CaCO}, \%)$ & 40 & 30 & 32.5 \\
Active carbonates $(\mathrm{CaCO}, \%)$ & 11.95 & 8.15 & 7.5 \\
Available $\mathrm{P}_{2} \mathrm{O}_{5}(\mathrm{mg} / \mathrm{kg})$ & 10.4 & 7.4 & 4.6 \\
Exchangeable $\mathrm{K}_{2} \mathrm{O}(\mathrm{mg} / \mathrm{kg})$ & 243 & 165.5 & 101 \\
Exchangeable $\mathrm{MgO}(\mathrm{mg} / \mathrm{kg})$ & 176 & 162 & 108.5 \\
Exchangeable $\mathrm{CaO}(\mathrm{mg} / \mathrm{kg})$ & 2520 & 2170 & 1634 \\
\hline
\end{tabular}

\subsection{Root System Distribution in P Compared to NP Vines}

Table 3 reports the root density and the average number of roots $/ \mathrm{m}^{2}$. After thirteen years from planting, the root system could be considered well established. In those conditions we found that the total root number $/ \mathrm{m}^{2}$ profile wall of the P vines was $\sim 2$ fold higher compared to NP vines at a $0.40 \mathrm{~m}$ distance from vine trunk, while this difference increased significantly to $\sim 10$ fold higher at a $1.00 \mathrm{~m}$ distance from vine trunk (Table 3 , root density $/ \mathrm{m}^{2}$ profile wall). In P treatments at the two distances from trunk, fine roots ( $<2 \mathrm{~mm}$ diameter) were the most abundant. The same results were observed in NP vines at $0.40 \mathrm{~m}$ distance, while at $1.00 \mathrm{~m}$ from the trunk intermediate roots (2-5 mm diameter) were the most abundant. In $\mathrm{P}$, there were more fine roots $(<2 \mathrm{~mm}$ diameter $)$ and intermediate roots (2-5 mm diameter) than in NP, both at the two distances from the trunk. Indeed, the thickest roots (> $5 \mathrm{~mm}$ diameter class) of NP vines were almost 2 fold more than those of $P$ vines at $0.40 \mathrm{~m}$, while at a $1.00 \mathrm{~m}$ distance there were more thick roots in P than in NP (Table 3). 
Table 2. Growing degree days (GDD, base $\left.10^{\circ} \mathrm{C}\right)$, rainfall $(\mathrm{mm})$, mean temperature of the years of study; mean temperature and rainfall from 1 st April to 30 th September; April-September monthly mean temperature and rainfall, at the experimental site in 2011 and 2012. Data from ARPAV (Agenzia Regionale per la Prevenzione e Protezione dell'Ambiente in Veneto).

\begin{tabular}{|c|c|c|c|c|c|c|c|c|c|c|c|c|c|c|c|c|c|}
\hline \multirow{2}{*}{ Year } & \multirow{2}{*}{$\begin{array}{c}\text { GDD } \\
\text { per Year }\end{array}$} & \multirow{2}{*}{$\begin{array}{c}\text { Rainfall } \\
\text { per Year } \\
(\mathrm{mm})\end{array}$} & \multirow{2}{*}{$\begin{array}{c}\text { T mean } \\
\text { per Year } \\
\left({ }^{\circ} \mathrm{C}\right)\end{array}$} & \multirow{2}{*}{$\begin{array}{c}\text { Rainfall } \\
\text { April-September } \\
(\mathrm{mm})\end{array}$} & \multirow{2}{*}{$\begin{array}{c}\text { T mean } \\
\text { April- September } \\
\left({ }^{\circ} \mathrm{C}\right)\end{array}$} & \multicolumn{2}{|c|}{ April } & \multicolumn{2}{|c|}{ May } & \multicolumn{2}{|c|}{ June } & \multicolumn{2}{|c|}{ July } & \multicolumn{2}{|c|}{ August } & \multicolumn{2}{|c|}{ September } \\
\hline & & & & & & T Mean & Rain & T Mean & Rain & T Mean & Rain & T Mean & Rain & T Mean & Rain & T Mean & Rain \\
\hline 201 & 1929 & 749.2 & 13.3 & 329.4 & 16.6 & 7 & 7 & 10.6 & 35.6 & 1 & 78.2 & 2 & 127.4 & 2 & 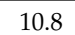 & 21 & 70 \\
\hline 2012 & 2010 & 836 & 13.3 & 450.8 & 17 & 7.4 & 126.6 & 10.8 & 101 & 15.7 & 19.8 & 24.5 & 13.6 & 24.4 & 57.8 & 19.2 & 132 \\
\hline
\end{tabular}


Table 3. Root density at two different distances from the vine trunk $(0.40$ and $1.00 \mathrm{~m})$, for $\varnothing<2.0 \mathrm{~mm}$ = fine roots; $2.0<\varnothing<5.0 \mathrm{~mm}=$ medium roots and $\varnothing>5.0 \mathrm{~mm}=$ permanent roots and for the total number of roots per profile wall. Data were recorded in January 2013, in no pruned (NP) and pruned (P) Pinot Gris vines, and are expressed as roots $/ \mathrm{m}^{2}$.

\begin{tabular}{|c|c|c|c|c|c|}
\hline \multirow{2}{*}{$\begin{array}{l}\text { Distance from } \\
\text { Vine Trunk (m) }\end{array}$} & \multirow[b]{2}{*}{ Treatment } & \multicolumn{3}{|c|}{$\begin{array}{c}\text { Root Density } \\
\text { (Number of Roots/m2 Profile Wall/Root Size) }\end{array}$} & \multirow{2}{*}{$\begin{array}{c}\text { Root Density } \\
\text { (Number of Roots/m² } \\
\text { Profile Wall) }\end{array}$} \\
\hline & & $\varnothing<2 \mathrm{~mm}$ & $2<\varnothing<5 \mathrm{~mm}$ & $\varnothing>5 \mathrm{~mm}$ & \\
\hline \multirow{3}{*}{0.40} & $\mathrm{NP}$ & $60.8 \mathrm{~b}$ & $10.5 \mathrm{~b}$ & $11.0 \mathrm{a}$ & $82.3 \mathrm{~b}$ \\
\hline & $\mathrm{P}$ & $100.8 \mathrm{a}$ & $25.8 \mathrm{a}$ & $6.3 \mathrm{~b}$ & $132.8 \mathrm{a}$ \\
\hline & Significance & $*$ & $*$ & $* *$ & $* *$ \\
\hline \multirow{3}{*}{1.00} & NP & $1.0 \mathrm{~b}$ & $2.5 \mathrm{~b}$ & $2.0 \mathrm{~b}$ & $6.0 \mathrm{~b}$ \\
\hline & $\mathrm{P}$ & $50.3 \mathrm{a}$ & $10.0 \mathrm{a}$ & $4.0 \mathrm{a}$ & $64.3 \mathrm{a}$ \\
\hline & Significance & ** & $* *$ & $*$ & $* *$ \\
\hline
\end{tabular}

For each distance from the vine trunk, within columns, values that are assigned by different letters are significantly different. Moreover; ${ }^{*}, * *$ and ${ }^{* * *}$ indicate significance at $\alpha \leq 0.05,0.01,0.001 \%$ and no significance (ns), respectively. Statistical analysis for the determination of significant differences between treatment means was carried out using the Student-Newman-Keuls test $(p \leq 0.05)$.

To examine the root vertical distribution in the soil, the number of roots calculated at each distance from the vine trunk $(0.40$ and $1.00 \mathrm{~m})$ in different soil layers was compared and presented as grapevine vertical root profiles (Figure 1). The root distribution differed between treatments and for both distances from the vine trunk. More precisely, at $0.40 \mathrm{~m}$ from the vine trunk, the maximum root density distribution of $\mathrm{P}$ was found in soil depths from 0 to $0.60 \mathrm{~m}$ with about $150 \mathrm{roots} / \mathrm{m}^{2}$ (Figure 1B). In the deeper layers $(0.80-1.00 \mathrm{~m})$, the density decreased but nevertheless remained high $\left(\sim 120 \mathrm{root} / \mathrm{m}^{2}\right)$. On the other hand, at the same vine trunk distance of $0.40 \mathrm{~m}$, the NP vines presented a 2 fold lower root density $\left(\sim 70\right.$ roots $\left./ \mathrm{m}^{2}\right)$ than the $P$ vines and for the same soil depth $(0-0.60 \mathrm{~m})$. Indeed, at $0.80-1.00 \mathrm{~m}$ of soil depth the NP vines registered the highest value of root density similarly to the $\mathrm{P}$ vines (Figure 1B). At a $1.00 \mathrm{~m}$ distance from the vine trunk root density was evidently different when the two treatments were compared, NP vines registering a constant and very low root density $\left(0-13 \mathrm{root} / \mathrm{m}^{2}\right)$ throughout all the soil layers compared to $\mathrm{P}$ vines; the latter registered an increasing root number at increasing soil depth up to almost $100 \mathrm{roots} / \mathrm{m}^{2}$ at $0.80-1.00 \mathrm{~m}$ soil depth (Figure $1 \mathrm{~A}$ ).
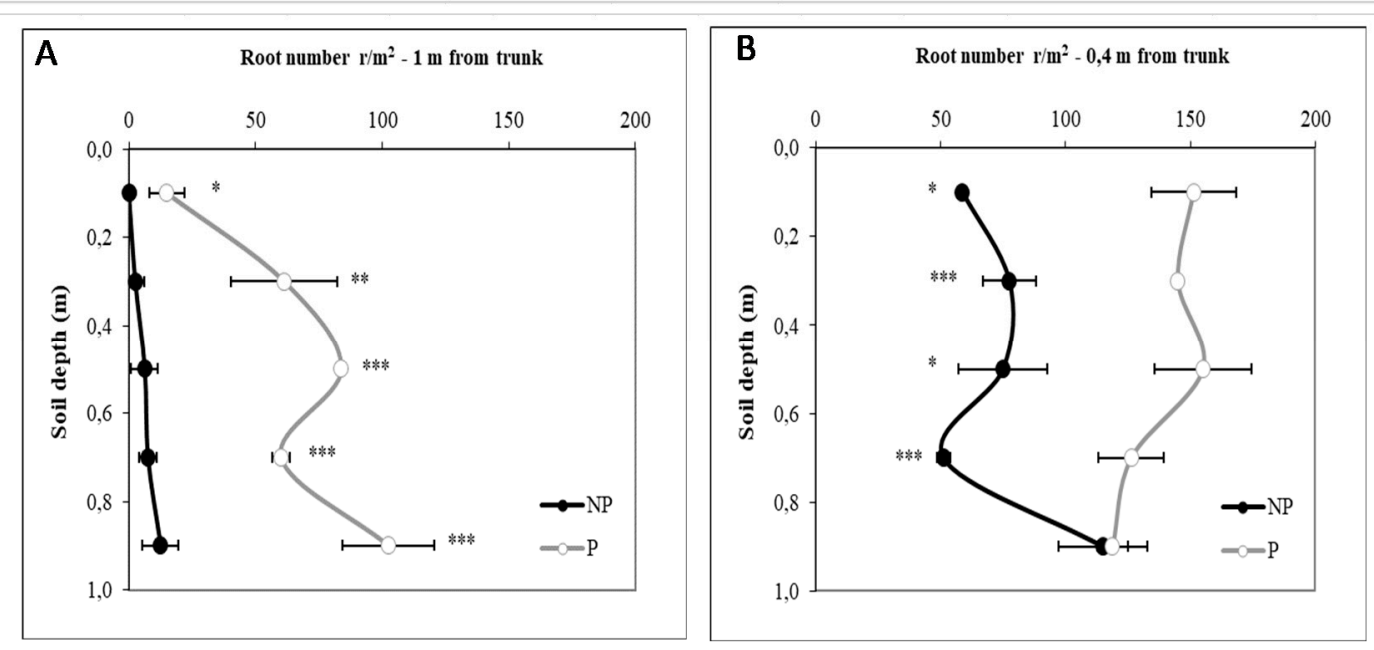

Figure 1. Root production (root number $/ \mathrm{m}^{2}$ ) by soil depth in no pruned (filled circles) and pruned (open circles) Pinot Gris vines, at $1.00 \mathrm{~m}(\mathbf{A})$ and $0.40 \mathrm{~m}(\mathbf{B})$ from vine trunk. ${ }^{*}, * * * * *$ indicate significance at $\alpha \leq 0.05,0.01,0.001 \%$ respectively, and no significance $(\mathrm{ns})$, of root observation $(\mathrm{n}=4)$. Bars denote 0.95 confidence intervals. Statistical analysis for the determination of significant differences between treatment means was carried out using the Student-Newman-Keuls test $(p \leq 0.05)$. 
Investigating the maximum root distribution in $\mathrm{P}$ and $\mathrm{NP}$ vines, in $\mathrm{P}$ the highest number of roots (almost $150 \mathrm{root} / \mathrm{m}^{2}$ ) were located at between 0 and $0.60 \mathrm{~m}$ soil depth and at $0.40 \mathrm{~m}$ distance from the vine trunk. Indeed, NP concentrated the majority of the roots at $0.80-1.00 \mathrm{~m}$ of soil depth at $0.40 \mathrm{~m}$ distance from the vine trunk. The scenario was totally the opposite at $1.00 \mathrm{~m}$ distance from the vine trunk, where $\mathrm{P}$ treatment registered the higher root density at $0.80-1.00 \mathrm{~m}$ of depth $\left(\sim 100 \mathrm{roots} / \mathrm{m}^{2}\right)$, while the NP treatment roots were evenly distributed in all soil layers but with very low, almost irrelevant, root density (Figure 1A,B).

The ratio between fine ( $<2 \mathrm{~mm}$ diameter) and thick ( $>5 \mathrm{~mm}$ diameter) roots, at a 0.40 and $1.00 \mathrm{~m}$ distance from the vine trunk was analysed. We found an average ratio of 4.6 and 3.1 at $0.40 \mathrm{~m}$ from the vine trunk, for P and NP, respectively. At $1.00 \mathrm{~m}$ distance from the vine trunk, values were lower, equal to 3.6 and 0.3 for $\mathrm{P}$ and $\mathrm{NP}$, respectively.

\subsection{Vine Growth, Leaf Area Development, Canopy Characteristics at Veraison, Yield and Grape Composition}

Results of canopy characterisation of the vines in the treatments are shown in Table 4. A significant difference in shoot number between $\mathrm{P}$ and NP vines was registered. Shoot number per vine was 89 and 101 in NP, against 35 and 75 in P vines, in 2011 and 2012, respectively. Shoots of NP vines presented shorter internodes and canes with a small diameter (data not shown), as often observed with minimal pruning in $V$. vinifera cultivars [41,42]. In accordance with the differences observed in shoot numbers, the total leaf area measured at veraison was higher in the NP treatment compared to $P$ (Table 4). Additionally, leave number in NP vines was higher than in P, in both years, while the leaf size of NP vines was smaller than that of $P$ vines, in both years of the experiment (Table 4).

Table 4. Canopy parameters, recorded at veraison over 2011-2012, in pruned (P) and no pruned (NP) Pinot Gris vines.

\begin{tabular}{ccccccc}
\hline & \multicolumn{3}{c}{$\mathbf{2 0 1 1}$} & \multicolumn{3}{c}{2012} \\
\cline { 2 - 7 } Parameter & $\mathbf{N P}$ & $\mathbf{P}$ & Significance & NP & $\mathbf{P}$ & Significance \\
\hline Shoots/vine & $89 \mathrm{a}$ & $35 \mathrm{~b}$ & $* *$ & $101 \mathrm{a}$ & $75 \mathrm{~b}$ & $*$ \\
Total leaf area/vine $(\mathrm{m} 2)$ & $8.5 \mathrm{a}$ & $6.9 \mathrm{~b}$ & $*$ & $9.7 \mathrm{a}$ & $4.9 \mathrm{~b}$ & $* *$ \\
Leaves number/vine & $2244 \mathrm{a}$ & $1446 \mathrm{~b}$ & $* *$ & $2496 \mathrm{a}$ & $1888 \mathrm{~b}$ & $* *$ \\
Leaf size (cm2) & $39 \mathrm{~b}$ & $49 \mathrm{a}$ & $*$ & $39 \mathrm{~b}$ & $50 \mathrm{a}$ & $*$ \\
\hline
\end{tabular}

For each year, within rows, values that are assigned by different letters are significantly different. Moreover; ${ }^{* * *}$ and ${ }^{* * *}$ indicate significance at $\alpha \leq 0.05,0.01,0.001 \%$ and no significance (ns), respectively. Statistical analysis for the determination of significant differences between treatment means was carried out using the Student-Newman-Keuls test $(p \leq 0.05)$.

Point Quadrat Analysis performed at the veraison stage, showed a significant difference between the treatments for the gap percentage during the experimental year 2011, while a non-significant difference was found between the treatments in 2012 (Table 5). Leaf layer number was significantly lower for pruned vines in 2011, while values were similar between the two treatments in 2012. In terms of the percentage of interior leaves, there was a significant difference between treatments only in 2011, with a high value in NP. The percentage of interior clusters was similar between treatments in both experimental years (Table 5). 
Table 5. Canopy characteristics from Point Quadrat analysis, recorded at veraison and over 2011-2012, in pruned $(\mathrm{P})$ and no pruned (NP) Pinot Gris vines.

\begin{tabular}{ccccccc}
\hline \multirow{2}{*}{ Parameter } & \multicolumn{3}{c}{$\mathbf{2 0 1 1}$} & \multicolumn{3}{c}{$\mathbf{2 0 1 2}$} \\
\cline { 2 - 7 } & $\mathbf{N P}$ & $\mathbf{P}$ & Significance & $\mathbf{N P}$ & $\mathbf{P}$ & Significance \\
\hline Gaps (\%) & $1 \mathrm{~b}$ & $5 \mathrm{a}$ & $* *$ & 0 & 0 & $\mathrm{~ns}$ \\
Leaf layer (number) & $7.1 \mathrm{a}$ & $4.5 \mathrm{~b}$ & $* *$ & 5.8 & 5.6 & $\mathrm{~ns}$ \\
Interior leaves (\%) & $71 \mathrm{a}$ & $55 \mathrm{~b}$ & $*$ & 70 & 64 & $\mathrm{~ns}$ \\
Interior clusters (\%) & 100 & 97 & $\mathrm{~ns}$ & 97 & 93 & $\mathrm{~ns}$ \\
\hline
\end{tabular}

For each year, within rows, values that are assigned by different letters are significantly different. Moreover; ${ }^{*}, * *$ and $* * *$ indicate significance at $\alpha \leq 0.05,0.01,0.001 \%$ and no significance (ns), respectively. Statistical analysis for the determination of significant differences between treatment means was carried out using the Student-Newman-Keuls test $(p \leq 0.05)$.

Finally, Table 6 reports yield components and berry chemical composition. Yield/vine was higher in NP, in 2011 and 2012, and more clusters/vine were observed in NP than P. In both years, the cluster weight (g) was higher in P. No significant differences were observed for berry chemical composition, except for titratable acidity in 2011.

Table 6. Yield, yield components, and berry chemical composition recorded at harvest over 2011-2012, in pruned $(\mathrm{P})$ and no pruned (NP) Pinot Gris vines.

\begin{tabular}{ccccccc}
\hline \multirow{2}{*}{ Parameter } & \multicolumn{3}{c}{$\mathbf{2 0 1 1}$} & \multicolumn{3}{c}{$\mathbf{2 0 1 2}$} \\
\cline { 2 - 7 } & $\mathbf{N P}$ & $\mathbf{P}$ & Significance & $\mathbf{N P}$ & $\mathbf{P}$ & Significance \\
\hline Yield/vine $(\mathrm{kg})$ & $5.0 \mathrm{a}$ & $2,03 \mathrm{~b}$ & $*$ & $4.5 \mathrm{a}$ & $3.6 \mathrm{~b}$ & $*$ \\
Clusters/vine & $108.2 \mathrm{a}$ & $30.0 \mathrm{~b}$ & $* *$ & $86.7 \mathrm{a}$ & $47.3 \mathrm{~b}$ & $* *$ \\
Cluster weight $(\mathrm{g})$ & 46.9 & 75.8 & $\mathrm{~ns}$ & $52.3 \mathrm{~b}$ & $76.5 \mathrm{a}$ & $*$ \\
Sugar content $\left({ }^{\circ}\right.$ Brix) & 18.5 & 19.6 & $\mathrm{~ns}$ & 20.5 & 20.3 & $\mathrm{~ns}$ \\
Titratable acidity $(\mathrm{g} / \mathrm{l})$ & $8.6 \mathrm{a}$ & $6.9 \mathrm{~b}$ & $*$ & 7.0 & 6.6 & $\mathrm{~ns}$ \\
pH & 3.2 & 3.41 & $\mathrm{~ns}$ & 3.39 & 3.45 & $\mathrm{~ns}$ \\
\hline
\end{tabular}

Within rows, for each year, values that are assigned by different letters are significantly different. Moreover; ${ }^{*}, * *$ and *** indicate significance at $\alpha \leq 0.05,0.01,0.001 \%$ and no significance (ns), respectively. Statistical analysis for the determination of significant differences between treatment means was carried out using the Student-Newman-Keuls test $(p \leq 0.05)$.

\subsection{Root Canopy Ratios}

In Table 7 we report root ratios between root-above-ground growth. Regarding root number/leaf area ratio, we observed a higher value in the $P$ vines than in the NP vines in both years of measurement $(2011,2012)$. The same trend was also seen in the root number/yield ratio, where we found a higher ratio for the P treatment than the NP, for both years of the study.

Table 7. Growth ratios, obtained from the root data recorded in January 2013 and the average leaf area and yield data recorded over 2011-2012, in pruned (P) and no pruned (NP) Pinot Gris vines.

\begin{tabular}{ccccc}
\hline \multirow{2}{*}{ Treatment } & \multicolumn{4}{c}{ Parameters } \\
\cline { 2 - 5 } & \multicolumn{2}{c}{ Root Number/Leaf Area } & \multicolumn{2}{c}{ Root Number/Yield } \\
& $\mathbf{2 0 1 1}$ & $\mathbf{2 0 1 2}$ & $\mathbf{2 0 1 1}$ & $\mathbf{2 0 1 2}$ \\
\hline NP & $10 \mathrm{~b}$ & $9 \mathrm{~b}$ & $15 \mathrm{~b}$ & $20 \mathrm{~b}$ \\
$\mathrm{P}$ & $19 \mathrm{a}$ & $29 \mathrm{a}$ & $58 \mathrm{a}$ & $34 \mathrm{a}$ \\
Significance & $*$ & $* *$ & $* *$ & $* *$
\end{tabular}

Within columns, values that are assigned by different letters, are significantly different. Moreover; ${ }^{*}, * *$ and ${ }^{* * *}$ indicate significance at $\alpha \leq 0.05,0.01,0.001 \%$ and no significance (ns), respectively. Statistical analysis for the determination of significant differences between treatment means was carried out using the Student-Newman-Keuls test $(p \leq 0.05)$. 


\subsection{Starch and Alcohol-Soluble Sugars in Roots and Canes}

Results for the total carbohydrate concentration (soluble sugars and starch) in one-year-old canes and in the roots are reported in Figure 2. Reserve substances were higher in the roots than in the canes in both treatments, NP and P. The concentration in the canes was similar in the two treatments (32.31 and $32.92 \mathrm{mg} / \mathrm{g}$ dry weight in NP and P, respectively). In the roots, the content was higher in NP (777.9 mg/g mg/g dry weight) than in P (555.5 mg/g dry weight).
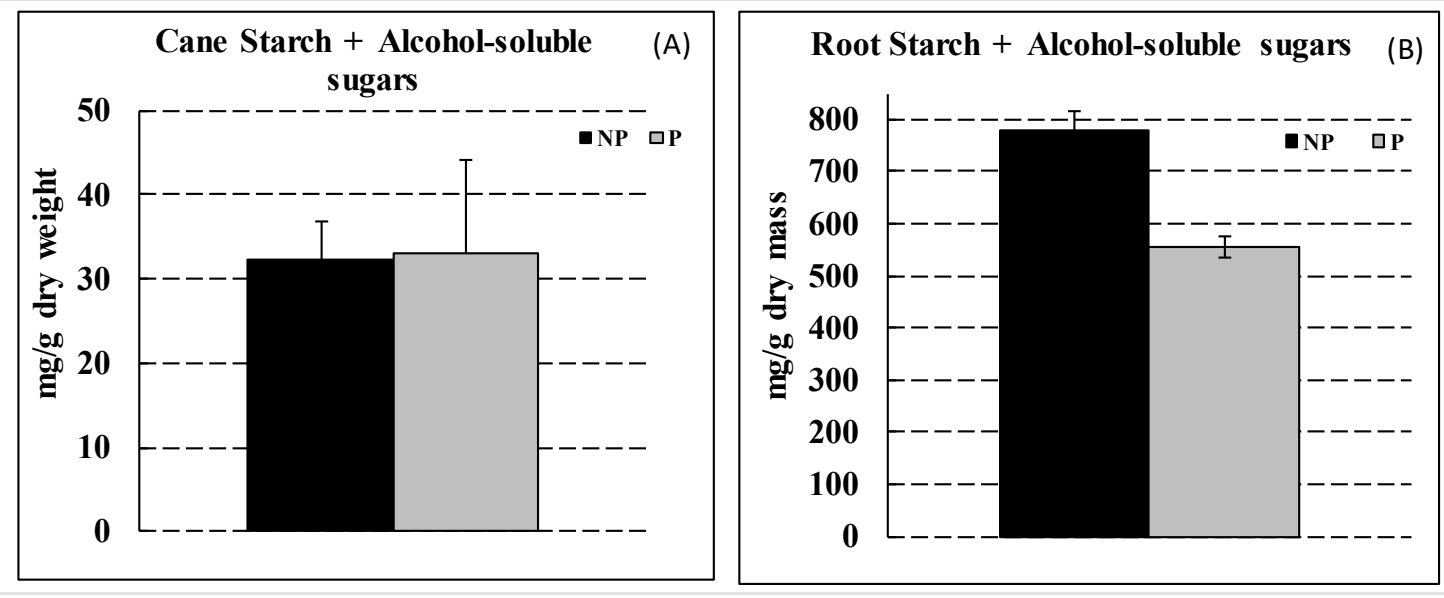

Figure 2. Cane starch + alcohol—soluble sugars (mg/g dry weight) (A), and root starch + alcohol-soluble sugars (mg/g dry weight) (B), in pruned (P) and no pruned (NP) Pinot Gris vines. Bars indicate standard error.

\section{Discussion}

Vine pruning is a normal practice adopted to control production and the quality of the grapes. Many studies on the effects of pruning on yield and yield composition are reported in literature $[43,44]$ but the knowledge of root development in relation to winter pruning is not yet well understood. Hence, the purpose of this study was to compare two treatments, pruning and no pruning, to analyse the effect of pruning on root distribution, density, and on the root sugar reserves. Root data were also analysed in relation to canopy growth and yield, to elucidate the effect of winter pruning on the root/canopy ratio.

The root survey performed after 13 years from planting demonstrated that pruning greatly influenced root density and distribution. The first evidence was on root number: the total number of roots was higher in the P treatment, where P especially produced more fine roots and medium size roots, while NP developed less roots altogether. Furthermore, the $\mathrm{P}$ treatment showed more roots per layer of depth than NP, both at $0.40 \mathrm{~m}$ and at $1.00 \mathrm{~m}$ from the vine trunk. We can conclude that the evidence of a higher number of roots in P was surveyed at $1.00 \mathrm{~m}$ from vine trunk, and still, $\mathrm{P}$ had a significantly higher number compared to NP. We can assume that the pruning stimulated not only the number of roots but also their arrangement along the soil profile and, consequently, their spreading, which is very important for nutrient and water absorption. We also analysed the ratio between fine and thick roots. An unpublished study by Archer and Hunter, 2005, reports the optimal ratio between fine/thick roots: below 3.0 the quality of the root system is indicated to be poor, between 3 and 3.5 it is good while above 3.5 it indicates a high-quality root system.

Vrsic et al., 2016 [45] confirmed that the ratio of fine/thick roots indicates the efficacy of the root system, with a low value-around 0.5/0.7-in agreement with the classification proposed by Archer and Hunter, 2005. Applying the index proposed by Archer and Hunter (2005) to our data, we can state a higher quality for $\mathrm{P}$ treatment compared to NP, at every distance from the vine trunk, but more pronounced at a $1.00 \mathrm{~m}$ distance. Furthermore, as previously indicated, pruning stimulates the development of fine roots rather than thick roots and this represents an advantage for the grapevine in several terms (absorption of water, nutrient uptake) (unpublished study by Archer and Hunter, 2005). 
As reported by Smart et al., 2006, [6] the root system architecture and rooting depth distribution depend on different factors, such as training systems, cultural practices, soil properties, and preparation. This confirms that vine pruning may influence root distribution, density and ratio of root sizes. Similar results regarding root density and growth were found by Hunter \& Le Roux, 1992 [46]. Having a more extensive root system is important for water and nutrient uptake as well as for exploration of soil and anchorage, which consequently leads to less requirements of inputs, improving the overall sustainability of the plant cultivation. In this context, it is important to achieve the stimulating effect of total roots, as well as the number of fine roots. In fact, fine and medium sized roots are responsible for water and nutrient uptake, while the main functions of the thick roots are anchorage and reserve [47,48].

Considering the competition between canopy and root system, higher root densities were expected to be found in pruned vines, and indeed, they were. In fact, $\mathrm{P}$ presented fewer shoots/vine, fewer leaves/vine, fewer grapes and consequently a lower yield, compared to NP. We can conclude that the increased yield and canopy have led to lower root density in NP. Perhaps with a more efficient root system, grapevines would be able to guarantee growth and production over the years, an information which has to be taken into consideration not only for the better uptake and exploitation of the soil resources but also in case of abiotic and/or biotic stress [22,49]. In this regard, Comas et al. (2005), in their study, reported that root production was influenced by carbon allocation, with a competition between roots and canopy, in agreement with our results. Hence, a proper and balanced root system not only positively influences the canopy development and the vegetative-productive ratio, it allows vines to cope with environmental factors: i.e., temperatures and water availability.

Point Quadrat Analysis was performed to better explore the pruning effect on the canopy structure and to explain the differences found between NP than P vegetative growth. Differences concerned gaps, leaf layer numbers, and interior leaves. In 2011 there were more gaps in P than in NP, and this was expected due to the larger canopy in NP, which led to a higher canopy development colonizing all the free space possible, while in 2012 the lack of differences could be explained with the higher amount of rainfall between April and May, which promoted a great vegetative growth in both treatments. Regarding leaf layer, in 2011, there were more layers in NP than in P. This could be explained with a better set up canopy in $\mathrm{P}$ than in NP, as an effect of the pruning. Furthermore, Viticare on farm trials-manual 3.3 (awri.com.au), reports that leaf layers should be less than 1.5 while the gap percentage should be $20-40 \%$, but we found a higher number of leaf layers and lower number of gaps. This must be explained by the fact that the training system adopted was a free cordon, meaning the canopy was shorter but thicker than a vertical canopy with 2 or 3 pairs of catch wire and upward shoots, which is the basic form suggested by the manual. In fact, a free cordon develops a canopy, which is more abundant in terms of downward shoots/vine and leaves and consequently more leaf layers. Similar results, for both measures, were found by De Bei (2008) [50]. Similar considerations can be extended also to the extremely high percentage of interior leaves and clusters in both treatments, values that nevertheless did not compromise the health of the grapes (data not shown).

Regardless of other measures associated with the ratio between the aerial part and the root system, the root number/leaf area ratio was higher in P treatments in 2011 and 2012. Similarly, root number/yield ratio was higher in P than in NP, in 2011 and 2012, due to the greater number of roots and the lower yield in P. In the same way, the evidence is that in NP there were more clusters and a higher yield/vine compared to P. The weight of the clusters was lighter in NP. This explanation is given because the production of roots is related to the reproductive allocation [51], the products of photosynthesis allocated in reproductive organs limits root growth; the general result is a higher yield and a lower root growth, in NP. This is also explained by the fact that the ability of the vines to produce dry matter is difficult to improve, in terms of absolute amount, through management practices [52].

Carbohydrates stored in the roots play a fundamental role in grapevines, as for all plants: they are important for winter survival and for the vegetative activity of the following season (budburst and early shoot growth) [53]. 
Examining the reserve substances in the canes and roots, indicated in starch plus alcohol-soluble sugar total content, we found a higher concentration in the roots than in the canes, as is reported in literature [53]. This, as widely recognised, is due to the fact that roots are the preferred organs for the accumulation of reserve substances [47]. In the experiment, specifically, the concentration was higher in the NP treatment than in P. This could be explained by considering that: (i) the total amount of roots was higher in $\mathrm{P}$, and most likely, for this reason the reserves were more diluted, and (ii) the NP treatment produced more thick roots, where starch is preferably accumulated [54]. The allocation of carbohydrates is partitioned in the aerial vegetative growth, the reproductive organs, and the roots, but the total amount of dry matter remains more or less the same [55]. In the experiment, the $\mathrm{P}$ treatment promoted root system growth at the expense of canopy and clusters, while the NP mostly affected the vegetative and reproductive parts rather than the roots.

\section{Conclusions}

Results from this study clearly indicated that winter pruning can influence the root system development and thereafter the root/canopy ratio.

In this study, winter pruning applied on mature Pinot Gris vines grafted onto $\mathrm{SO} 4$ rootstock stimulated root growth and distribution without compromising the canopy development in terms of a normal canopy generally found in pruned vineyards. On the contrary, the no prune treatment showed a lower root density and distribution, but a larger canopy compared to pruned vines. Differences in root/canopy ratio found between P and NP treatments clearly demonstrated that winter pruning contributes to determine the development of wider subterranean parts of the plant (composed mainly of fine roots). In our study, no pruned treatment favoured the canopy development, disadvantaging root growth. Winter pruning led to a better ratio between the above- and below-ground structures of the plant, with the advantage of having a good vegetative-productive balance capable of achieving yield and quality purposes.

Therefore, vine pruning is an agronomic practice that allows us to achieve a better and consistent vine balance and arrangement.

Author Contributions: Conceptualization, G.M.; methodology, N.B., F.G., L.L., D.P.; software, G.M.; validation, D.T. and F.G.; formal analysis, F.G.; data curation, G.M.; writing—original draft preparation, G.M.; writing - review and editing, G.M., F.G., D.T., D.B. and N.B. All authors have read and agreed to the published version of the manuscript.

Funding: This research received funding from the "OIGA-VINSALUT" project, MIIPAF.

Acknowledgments: The authors thank "Le Rive" winery for their kind support offered during the experimental years.

Conflicts of Interest: The authors declare no conflict of interest.

\section{References}

1. Conradie, W.J. Seasonal uptake of nutrients by chenin blanc in sand culture: I. Nitrogen. South Afr. J. Enol. Vitic. 1980, 1, 59-65. [CrossRef]

2. Porro, D.; Ramponi, M.; Rolle, L.; Tomasi, T.; Poni, S. Nutritional implications of water stress in grapevine and modifications of mechanical properties of berries. Acta Hortic. 2010, 868, 73-80. [CrossRef]

3. Morlat, R.; Jacquet, A. Grapevine root system and soil characteristics in a vineyard maintained long-term with or without interrow sward. Am. J. Enol. Vitic. 2003, 54,1-7.

4. Hunter, J.J.; Volschenk, C.G. Effect of altered canopy: Root volume ratio on grapevine growth compensation. South Afr. J. Enol. Vitic. 2001, 22, 27-30.

5. Morano, L.; Kliewer, W.M. Root distribution of three grapevine rootstocks grafted to Cabernet Sauvignon Grown on a very gravelly clay loam soil in Oakville, California. Am. J. Enol. Vitic. 1994, 45, 345-348.

6. Smart, D.R.; Schwass, E.; Lakso, A.; Morano, L. Grapevine rooting patterns: A comprehensive analysis and a review. Am. J. Enol. Vitic. 2006, 57, 89-104.

7. Archer, E.; Strauss, H.C. The effect of plant spacing on the water status of soil and grape-vines. South Afr. J. Enol. Vitic. 2017, 10. [CrossRef] 
8. Korboulewsky, N.; Robles, C.; Garzino, S. Effects of sewage sludge compost on volatile organic compounds of wine from Vitis vinifera cv. red grenache. Am. J. Enol. Vitic. 2004, 55, 412-416.

9. Morlat, R.; Jacquet, A. The soil effects on the grapevine root system in several vineyards of the Loire vane. y (France). VITIS J. Grapevine Res. 2015, 32, 35.

10. Bengough, A.G.; Mullins, C.E. Penetrometer resistance, root penetration resistance and root elongation rate in two sandy loam soils. Plant Soil. 1991, 131, 59-66. [CrossRef]

11. Tomasi, D.; Battista, F.; Gaiotti, F.; Mosetti, D.; Bragato, G. Influence of soil on root distribution: Implications for quality of tocai friulano berries and wine. Am. J. Enol. Vitic. 2015, 66, 363-372. [CrossRef]

12. Van Zyl, J.L.; van Huyssteen, L. Comparative studies on wine grapes on different trellising systems: II. Micro-climatic studies, grape composition and wine quality. South Afr. J. Enol. Vitic. 2017, 1, doi. [CrossRef]

13. Mapfumo, E.; Aspinall, D. Anatomical changes of grapevine (Vitis vinifera L. cv. Shiraz) roots related to radial resistance to water movement. Aust. J. Plant Physiol. 1994, 21, 437-447. [CrossRef]

14. Freeman, B.M.; Smart, R.E. A root observation laboratory for studies with grapevines. Am. J. Enol. Vitic. 1976, 27, 36-39.

15. Withington, J.M.; Reich, P.B.; Oleksyn, J.; Eissenstat, D.M. Comparison of structure and life span in roots and leaves among temperate trees. Ecol. Monogr. 2006, 76, 381-397. [CrossRef]

16. Comas, L.H.; Bauerle, T.L.; Eissenstat, D.M. Biological and environmental factors controlling root dynamics and function: Effects of root ageing and soil moisture. Aust. J. Grape Wine Res. 2010, 16, 131-137. [CrossRef]

17. Gaiotti, F.; Marcuzzo, P.; Belfiore, N.; Lovat, L.; Fornasier, F.; Tomasi, D. Influence of compost addition on soil properties, root growth and vine performances of Vitis vinifera cv Cabernet sauvignon. Sci. Hortic. 2017, 225, 88-95. [CrossRef]

18. Júnior, A.F.N.; Amorim, L.; Savary, S.; Willocquet, L. Modelling the dynamics of grapevine growth over years. Ecol. Model. 2018, 369, 77-87. [CrossRef]

19. Celette, F.; Gaudin, R.; Gary, C. Spatial and temporal changes to the water regime of a Mediterranean vineyard due to the adoption of cover cropping. Eur. J. Agron. 2008, 29, 153-162. [CrossRef]

20. Torres, R.L.; Lloreda, M.D.L.F.; Gonzalez, P.J.; Garcia-Gutierrez, J.R.L.; Trujillo, P.B. Effect of soil management strategies on the characteristics of the grapevine root system in irrigated vineyards under semi-arid conditions. Aust. J. Grape Wine Res. 2018, 24, 439-449. [CrossRef]

21. Hunter, J.J.; Ruffner, H.P.; Volschenk, C.G.; Le Roux, D.J. Partial defoliation of vitis vinifera L. cv. Cabernet Sauvignon/99 richter: Effect on root growth, canopy efficiency; grape composition, and wine quality. Am. J. Enol. Vitic. 1995, 46, 306-314.

22. Comas, L.H.; Anderson, L.J.; Dunst, R.M.; Lakso, A.N.; Eissenstat, D.M. Canopy and environmental control of root dynamics in a long-term study of Concord grape. New Phytol. 2005, 167, 829-840. [CrossRef] [PubMed]

23. Anderson, L.J.; Comas, L.H.; Lakso, A.N.; Eissenstat, D.M. Multiple risk factors in root survivorship: A 4-year study in Concord grape. New Phytol. 2003, 158, 489-501. [CrossRef]

24. Hunter, J.J.; Archer, E.; van Schalkwyk, D.; Strever, A.E.; Volschenk, C.G. Grapevine roots: Interaction with natural factors and agronomic practices. Acta Hortic. 2016, 1136, 63-80. [CrossRef]

25. Buttrose, M.; Mullins, M. Proportional reduction in shoot growth of grapevines with root systems maintained at constant relative volumes by repeated pruning. Aust. J. Biol. Sci. 1968, 21, 1095. [CrossRef]

26. Kliewer, W.M.; Fuller, R.D. Effect of time and severity of defoliation on growth of roots, trunk, and shoots of “Thompson Seedless" grapevines. Am. J. Enol. Vitic. 1973, 24, 59-64.

27. Giese, G.; Wolf, T.K.; Velasco-Cruz, C.; Roberts, L.; Heitman, J. Cover crop and root pruning impacts on vegetative growth, crop yield components, and grape composition of cabernet sauvignon. Am. J. Enol. Vitic. 2015, 66, 212-226. [CrossRef]

28. Saayman, D. Soil preparation studies: II. The effect of depth and method of soil preparation and of organic material on the performance of vitis vinifera (var. Colombar) on Clovelly/Hutton Soil. South Afr. J. Enol. Vitic. 2017, 3, 61-74. [CrossRef]

29. Volschenk, C.G.; Hunter, J.J. Effect of seasonal canopy management on the performance of chenin blanc/99 richter grapevines. South Afr. J. Enol. Vitic. 2017, 22, 36-40. [CrossRef]

30. Bates, T. Pruning level affects growth and yield of New York Concord on two training systems. Am. J. Enol. Vitic. 2008, 59, 276-286.

31. Gatti, M.; Civardi, S.; Bernizzoni, F.; Poni, S. Long-term effects of mechanical winter pruning on growth, yield, and grape composition of barbera grapevines. Am. J. Enol. Vitic. 2011, 62, 199-206. [CrossRef] 
32. Intrieri, C.; Filippetti, I.; Allegro, G.; Valentini, G.; Pastore, C.; Colucci, E. The semi-minimal-pruned hedge: A novel mechanized grapevine training system. Am. J. Enol. Vitic. 2011, 62, 312-318. [CrossRef]

33. Morris, J.R.; Main, G.L.; Oswald, O.L. Flower cluster and shoot thinning for crop control in French-American hybrid grapes. Am. J. Enol. Vitic. 2004, 55, 423-426.

34. Richards, D. The grape root system. Hortic. Rev. 2011, 5, 127-168. [CrossRef]

35. MIIPAF (Ministry of Agricultural, Food and Forestry Policies), DL 79/92. Decreto Legislativo 11 maggio. Gazzetta Ufficciale. 25 May 1992. n. 121. Available online: https://www.gazzettaufficiale.it/eli/id/1992/05/25/ 092A2322/sg (accessed on 11 August 2020).

36. MIIPAF (Ministry of Agricultural, Food and Forestry Policies), DL 185/99. Decreto Legislativo 13 settembre. Gazzetta Ufficiale. 21 October 1999. n. 248. Available online: https://www.gazzettaufficiale.it/eli/id/1992/05/ 25/092A2322/sg (accessed on 11 August 2020).

37. Bohm, W. Methods of Studying Root Systems; Springer: Berlin/Heidelberg, Germany, 1979.

38. Smart, R.E.; Robinson, M. Sunlight into Wine: A Handbook for Wine Grape Canopy Management. Wine Titles, Adelaide-References-Scientific Research Publishing. Available online: https://www. scirp.org/(S(lz5mqp453edsnp55rrgjct55))/reference/ReferencesPapers.aspx?ReferenceID=1464824 (accessed on 21 February 2020).

39. Loewus, F.A. Improvement in anthrone method for determination of carbohydrates. Anal. Chem. 1952, 24, 219. [CrossRef]

40. Proffitt, T.; Campbell-Clause, J. Managing Grapevine Nutrition and Vineyard Soil Health. Available online: www.winewa.asn.au (accessed on 17 January 2020).

41. Jackson, D.I.; Lombard, P.B.; Kabinett, L.Q. Environmental and management practices affecting grape composition and wine quality-A review. Am. J. Enol. Vitic. 1993, 44, 409-430.

42. Possingham, J.V. New concepts in pruning grapevines. In Horticultural Reviews; John Wiley \& Sons, Inc.: Oxford, UK, 2010; pp. 235-254.

43. Wessner, L.F.; Kurtural, S.K. Pruning systems and canopy management practice interact on the yield and fruit composition of Syrah. Am. J. Enol. Vitic. 2013, 64, 134-138. [CrossRef]

44. Mann, G.V.; Newton, P. The membrane transport of ascorbic acid. Ann. N. Y. Acad. Sci. 1975, 258, $243-252$. [CrossRef]

45. Vršič, S.; Kocsis, L.; Pulko, B. Influence of substrate $\mathrm{pH}$ on root growth, biomass and leaf mineral contents of grapevine rootstocks grown in pots. J. Agric. Sci. Technol. 2016, 18, 483-490.

46. Hunter, J.J.; Le Roux, D.J. The Effect of partial defoliation on development and distribution of roots of vitis vinifera 1. cv. cabernet sauvignon grafted onto rootstock 99 richter. Am. J. Enol. Vitic. 1992, 43, 71-78.

47. Corso, O.D.E.L. Arboricoltura Generale per la Laurea Triennale in Scienze Agrarie; Editor: Pàtron: Bologna, Italy, 2015.

48. Anderson, E.L. Tillage and N fertilization effects on maize root growth and root:shoot ratio. Plant Soil 1988, 108, 245-251. [CrossRef]

49. Comas, L.H.; Eissenstat, D.M.; Lakso, A.N. Assessing root death and root system dynamics in a study of grape canopy pruning. New Phytol. 2000, 147, 171-178. [CrossRef]

50. De Bei, R. Evidenze Viticole ed Enologiche Indotte Dalla Disposizione Della Vegetazione E Dalla Lunghezza del Capo a Frutto Nelle Varietà Cabernet Sauvignon, Merlot e Pinot Grigio. Ph.D. Thesis, Universita degli Studi di Padova, Padova, Italy, 2008.

51. Soppelsa, S.; Kelderer, M.; Casera, C.; Bassi, M.; Robatscher, P.; Matteazzi, A.; Andreotti, C. Foliar Applications of Biostimulants promote growth, yield and fruit quality of strawberry plants grown under nutrient limitation. Agronomy 2019, 9, 483. [CrossRef]

52. Edson, C.E.; Howell, G.S.; Flore, J.A. Influence of crop load on photosynthesis and dry matter partitioning of seyval grapevines I. Single leaf and whole vine response pre- and post-harvest. Am. J. Enol. Vitic. 1993, 44, 139-147.

53. Loescher, W.H.; Mccamant, T.; Keller, J.D. Carbohydrate reserves, translocation, and storage in woody plant roots. HortScience 1990, 25, 274-281. [CrossRef] 
54. Savè, R.; Sabatè, S.; de Herralde, F.; Biel, C.; Miguel, C.; Alsina, M.M.; Fortea, G.; Grau, B.; Vilanova, A.; Tomas, E.; et al. Could be the Root System of Cultured Plants an Important Carbon Sink Under Global Change Conditions? In Proceedings of the 8th International $\mathrm{CO}_{2}$ Conference, 2009, Jena, Germany, 13-19 September 2009.

55. Petrie, P.R.; Trought, M.C.T.; Howell, G.S. Growth and dry matter partitioning of Pinot Noir (Vitis vinifera L.) in relation to leaf area and crop load. Aust. J. Grape Wine Res. 2000, 6, 40-45. [CrossRef]

(C) 2020 by the authors. Licensee MDPI, Basel, Switzerland. This article is an open access article distributed under the terms and conditions of the Creative Commons Attribution (CC BY) license (http://creativecommons.org/licenses/by/4.0/). 